\title{
China unveils green targets
}

\section{Premier vows to improve energy efficiency and curb pollution and carbon emissions.}

\section{BY JANE QIU}

G rowing environmental costs and energy demands have persuaded China's leaders that the country cannot sustain its breakneck economic growth. In a speech on Saturday at the annual National Party Congress in Beijing, Premier Wen Jiabao announced ambitious five-year goals for increasing energy efficiency and curbing carbon emissions - and a reduced target for economic growth.

In the past five years, China's gross domestic product (GDP) has increased at an average rate of $11.2 \%$ a year. The country has reduced its energy intensity - or energy consumption per unit of GDP - by $19.1 \%$, just short of a $20 \%$ target set five years ago. Emissions of chemical oxygen demand (a measure of organic pollutants in water) and sulphur dioxide per unit of GDP also dipped by $12.5 \%$ and $14.3 \%$ respectively, exceeding previous targets of $10 \%$.

The latest five-year plan has lowered the economic-growth target to around $7 \%$ a year, and calls for energy intensity to decline by a further $16 \%$. The plan is China's first to include targets for carbon emissions per unit of GDP - to be reduced by $17 \%$ - and total energy use, which will be capped at 4 billion tonnes of coal equivalent by 2015 , compared with the 3.25 billion tonnes consumed last year (see 'Goals for 2015').

"The targets are very ambitious in global terms," says Antony Froggatt, a climate and environment policy expert at Chatham House, a think tank in London that focuses on international affairs. But because the country's imports of coal, oil and gas are increasing each year, he says, the goals "are crucial for China to become competitive on the global market".

The plans are in line with China's existing aim to reduce carbon intensity by $40-45 \%$ from 2005 levels by 2020 (see Nature 462, 550-551; 2009). Froggatt notes, however, that the commitments fall short of what some climate-policy experts regard as a sufficient contribution towards the current international

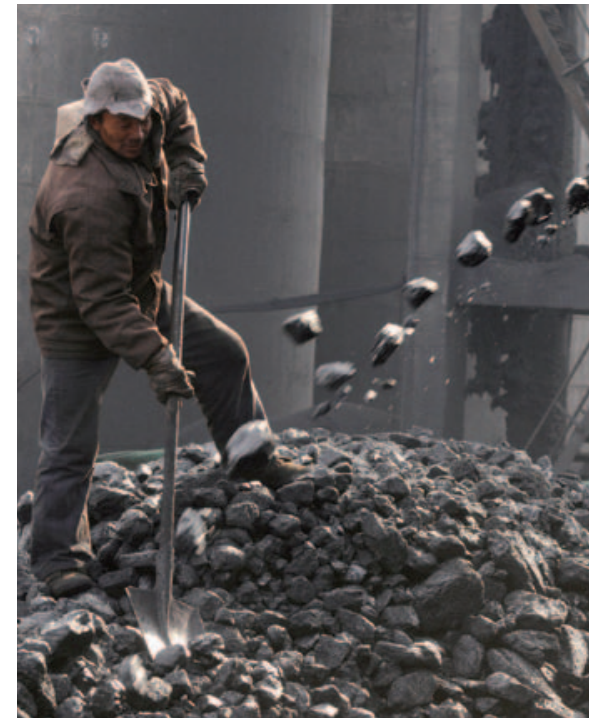

China plans to reduce its reliance on coal by upping energy efficiency and the use of non-fossil fuels.

goal of preventing the world's temperature from increasing by $2{ }^{\circ} \mathrm{C}$ over the pre-industrial level. "But China is not alone in that," he adds.

To meet its targets, China will scrutinize its entire energy-production chain, from suppliers to transmission and end users, and will inspect industries sector by sector, looking for ways to increase efficiency. The country also aims to raise the proportion of its energy coming from non-fossil fuels - notably, wind energy, hydropower and nuclear power - to $11.4 \%$ by 2015 . The government hopes that plans to increase spending on research and development to $2.2 \%$ of GDP - significantly higher than today will yield breakthroughs in clean energy.

Critics applaud China's plan to cut energy and carbon intensities, but say that the question is not just whether the targets will be enforced, but how. "Low-carbon economy is not just about number crunching," says Zou $\mathrm{Ji}$, an environmental economist at Renmin University in Beijing. "There are different

\section{FIVE-YEAR PLANNING Goals for 2015}

- Reduce energy and carbon intensity by $16 \%$ and $17 \%$, respectively. - Cap energy use at 4 billion tonnes of coal equivalent.

- Increase the proportion of non-fossil fuels to $11.4 \%$ from the current $8.3 \%$. - Reduce emissions of chemical oxygen demand and sulphur dioxide by $8 \%$.

- Reduce emissions of ammonia and nitrogen oxides by $10 \%$.

- Increase forest coverage to $21.7 \%$.

- Increase timber reserve by 600 million cubic metres.

- Reduce water use per unit of industrial growth by $30 \%$.

- Increase efficiency of irrigation to 53\%.

ways to meet the targets, and some are more cost-effective and sustainable than others."

Many say that China met the previous energy-intensity target largely through draconian government measures, such as strict quotas imposed on local governments and energy-intensive industries. Fear of missing their targets led some provinces to severely ration power in the latter half of last year. This "is not necessarily the most cost-effective approach”, says Kelly Gallagher, who studies energy and environment policy at Tufts University in Medford, Massachusetts.

The transition to a low-carbon economy requires not only technological innovation, but also drastic reforms in energy pricing, along with mechanisms such as emissions trading and carbon taxation, says Zou. "These are on the agenda of the central government, in principle," he says. "Whether they can be implemented in the next few years will determine the future of China's economic competitiveness." -

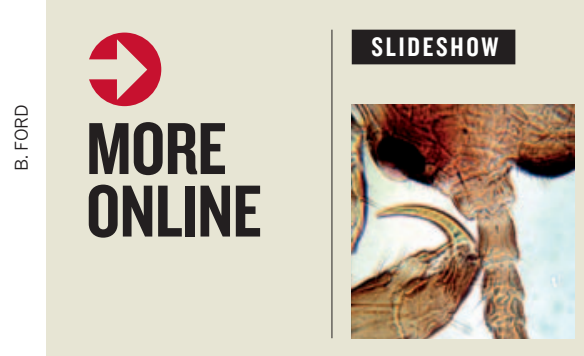

Images from the first microscopes were clearer than was once believed go.nature. com/xvukmb

\section{NEWS}

- Satellite monitoring shows oil palms crowding out peat swamps in Malaysia go.nature.com/rmbbrv

- Stretchy electronics could speed up heart surgery go.nature.com/yvusf8

- Is this the end of the Guinness widget? go.nature.com/rkmvrg

\section{ONLINE POLL}

How does the Internet influence the way you work? What do you do to manage your online reputation? Take part in Nature's online survey about the web and you could win an Amazon gift certificate worth $£ 100$ / US\$150 go.nature.com/9xpdpn 